\title{
Chick production by in vitro fertilization of the fowl ovum
}

\author{
K. Tanaka ${ }^{1}$, T. Wada ${ }^{1}$, O. Koga ${ }^{1}$, Y. Nishio ${ }^{2}$ and \\ F. Hertelendy ${ }^{3 *}$ \\ ${ }^{1}$ Faculty of Agriculture, Kyushu University, Fukuoka 812, Japan, ${ }^{2}$ Fukuoka Agriculture Research \\ Station, Chikushino-shi 818, Japan; and ${ }^{3}$ Department of Obstetrics and Gynecology, St Louis \\ University Medical Center, St Louis, MO 63110-0250, USA
}

\begin{abstract}
The aim of this study was to produce viable chicks by in vitro fertilization and transfer of fertilized ova to the oviduct of recipient hens. Out of a total of 76 transferred ova, 53 were laid with fully calcified shells, 31 of which were fertile $(58 \%)$. Despite the high rate of embryonic loss, six live chicks were hatched from 12 fertile ova exposed to $0.05 \mathrm{ml}$ of semen ( $1: 200$ dilution). Nine healthy chicks were hatched from ten control ova which were recovered from the oviduct following artificial insemination and subsequent transfer to recipient hens. This experimental approach provides a useful model for production of transgenic chicks.
\end{abstract}

\section{Introduction}

Establishment of an in vitro culture method that would allow the fertilized ovum to develop into a hatchling could provide a useful means for genetic manipulation in domestic fowl. Freeman and Messer (1985) concluded that there were two outstanding problems, namely, establishing techniques for gene selection and devising methods for insertion of genetic material. Embryos $(72 \mathrm{~h})$ have been successfully cultured in surrogate eggshells to hatchlings by Rowlett and Simkiss (1987). Perry (1988) developed a complete culture system from embryo to hatching. Embryos of single-cell stage collected from the magnum were transferred to eggshells and cultured by three elaborate steps. Two healthy chicks were obtained $(3 \%)$ and three weaklings ( $4 \%$ ). Naito et al. (1990) improved this method and obtained a higher rate of hatchability $(34.4 \%)$. Naito et al. (1991) incorporated the $\beta$-actin-lacZ hybrid gene, MiwZ, using the Naito-Perry system. They obtained day 4 embryos (64\%) expressing MiwZ, but most of the embryos were of mosaic expression. The successful production of chicks by in vitro fertilization (IVF) could accomplish two important objectives. It would allow the production of transgenic fowl, as well as resolve the issue of capacitation of fowl spermatozoa. This could provide additional evidence to the observation by Howarth (1971) and Fujihara et al. (1973), who used a culture method and postulated that fowl spermatozoa did not require a period of capacitation within the reproductive tract of the hen.

The objective of the present study was to produce chicks by IVF, by returning the fertilized ovum into the oviduct of a recipient hen to complete the egg and shell formation, allowing subsequent incubation.

\section{Materials and Methods}

Clean semen was collected by a one-man technique (Bogdonoff and Schaffner, 1954) from four Rhode Island Red roosters aged 7-14 months. The number of spermatozoa in the pooled semen was $29.2( \pm 1.4) \times 10^{8} \mathrm{ml}^{-1}$. Since a phosphate buffer (Wilcox and Schaffner, 1958) was used as suitable diluent for the preservation of fowl semen, the pooled semen was diluted $\mathrm{I}: \mathrm{I}$ with the phosphate buffer containing I $\mathrm{g}$ streptomycin sulfate $\mathrm{I}^{-1}$ and $1000 \mathrm{U}$ crystalline penicillin $\mathrm{I}^{-1}$ (Meiji Co. Tokyo). A schematic presentation of IVF procedure is shown in Fig. 1. Virgin hens of White Leghorn strain, 6-10 months old were killed with an overdose of Nembutal (Abbott Labs, Chicago, IL) 25 min after oviposition and the ovulated ovum was recovered from the abdominal cavity or from the infundibulum. Each ovum was placed in a $100 \mathrm{ml}$ beaker containing about $80 \mathrm{ml}$ of modified Ringer's solution which consisted of (in mmol l-1) $145 \mathrm{NaCl}, 2.68 \mathrm{KCl}, 1.80 \mathrm{CaCl}_{2}$ $0.24 \mathrm{NaHCO}_{3}, 1 \mathrm{~g}$ streptomycin sulfate $\mathrm{I}^{-1}$ and $1000 \mathrm{U}$ crystalline penicillin $1^{-1}$. (Whenever reference is made to Ringer's solution or phosphate buffer, it always contained antibiotics as above.) The twofold diluted semen was further extended 1:100 with Ringer's solution just before application of $0.01-0.10 \mathrm{ml}$ directly over the blastodisc of the immersed ovum (Howarth and Palmer, 1972), followed by incubation at $41^{\circ} \mathrm{C}$ for $15 \mathrm{~min}$ to allow for in vitro fertilization. The ova were then washed twice in $300 \mathrm{ml}$ Ringer's solution to remove the spermatozoa, and they were kept at $41^{\circ} \mathrm{C}$ individually in $100 \mathrm{ml}$ beakers containing fresh Ringer's solution

Within a few minutes after oviposition of a midsequence egg, hens were anaesthetized with Nembutal (about $0.8 \mathrm{ml}$ ) and an incision, approximately $6 \mathrm{~cm}$ long, was made on the left side of the abdomen. The infundibulum was exteriorized and affixed with three clamps on a horizontal bar of a stand. The washed ovum was poured from a beaker into the open infundibulum. After removing the clips, the infundibulum was gently shaken to move the ovum into the anterior portion of the magnum.

*Correspondence.

Received 18 May 1993. 


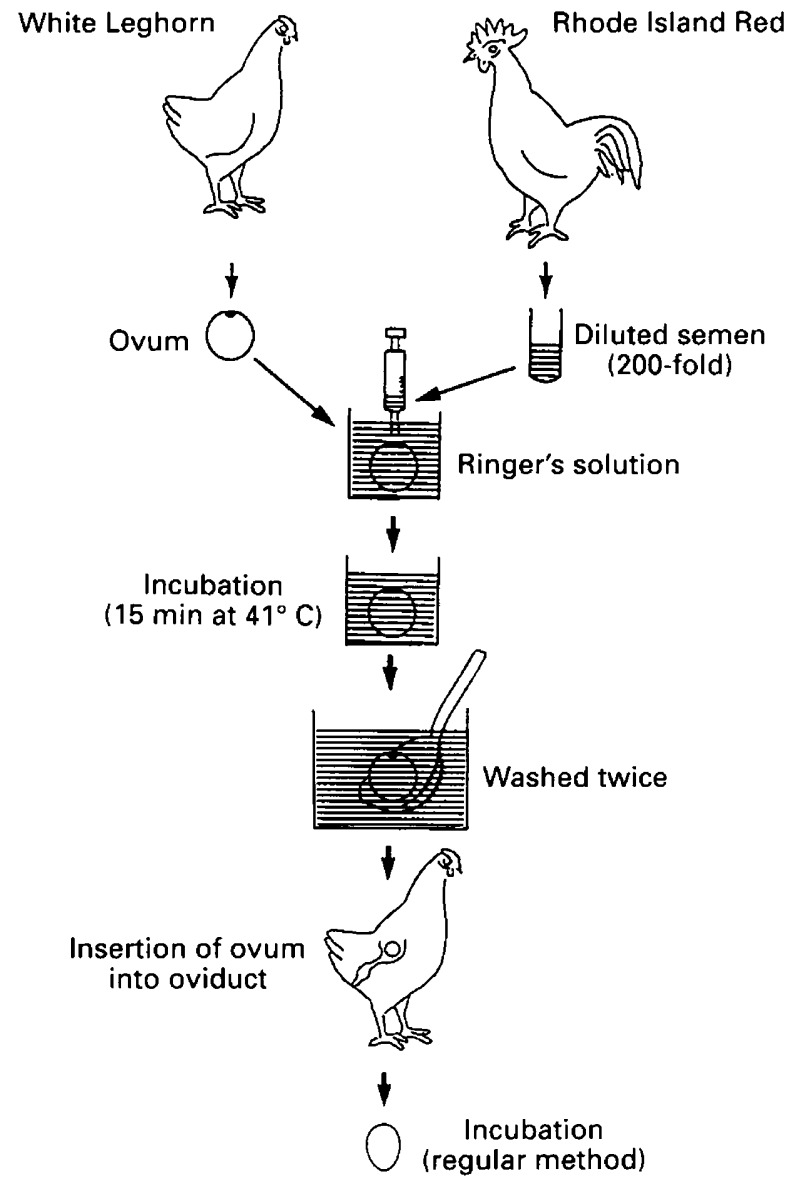

Fig. 1. Schematic representation of IVF procedure. Unfertilized ovum was placed in a beaker containing Ringer's solution and diluted semen $(0.01-0.10 \mathrm{ml})$ was placed over the blastodisc. The ovum was then washed twice with Ringer's solution and inserted into the oviduct of a virgin hen shortly after oviposition. The egg laid on the following day was incubated.

The incision was then closed. Care was taken not to leave trapped air inside the oviduct, and to minimize the duration of the operation, to avoid undue stress to the hens. The entire procedure was performed under sterile conditions. Eggs laid on the day following the transfer of the ovum into the oviduct were completely normal in appearance, and were placed in an incubator for hatching under standard conditions. As a control, pooled semen collected from the same four roosters used in this study was diluted $1: 1$ with phosphate buffer and $0.1 \mathrm{ml}$ was used for each of ten hens to inseminate intravaginally. Two days after insemination, the hens were killed by an overdose of Nembutal $\mathrm{Ih}$ after oviposition and the ova were recovered from the infundibulum or the anterior part of the magnum. The ova were placed separately in a $100 \mathrm{ml}$ beaker containing Ringer's solution until transfer to virgin recipient hens, as described above. On the next day all 10 hens laid fully calcified eggs, which were then placed in a standard incubator.

\section{Results}

Embryos that died during incubation were classified into three groups, according to their developmental stages (Hamburger and Hamilton, 1951) as shown (Table 1). Of a total of 86 transferred ova, 63 shelled eggs $(73 \%)$ were produced on the day after transfer. The rates of production of shelled eggs and fertility were comparable among the three experimental groups using increasing volume of semen $(0.01-0.10 \mathrm{ml})$. However, only in the group in which $0.05 \mathrm{ml}$ semen was used were six fertilized eggs (50\%) hatched. Of these, four chicks were healthy and two died during incubation (Table 1). There was a high incidence of early embryonic death between days 1 and 9 in all three experimental groups, but there was no significant difference in the embryonic mortality among the three incubation periods and among the three semen applications. By comparison, all ten ova transferred in the control group were laid shelled, of which nine eggs were hatched and one embryo died after incubation for 2 days. There was a significant difference in early embryonic mortality and hatchability between IVF and inseminated control groups $(P<0.05)$.

\section{Discussion}

This study demonstrated that fertile eggs can be obtained by IVF of ova removed shortly after ovulation and subsequently transplanted into the oviduct of recipient hens. It was important that the ovum was inserted into the infundibulum immediately or shortly after oviposition, otherwise shelled eggs were seldom laid. In addition, the ovum should be located in the anterior magnum before closing the incision, to avoid

Table 1. Percentage of fertilized eggs laid and viability of embryos following transfer of in vitro or in vivo fertilized ova to recipient hens

\begin{tabular}{|c|c|c|c|c|c|c|c|}
\hline \multirow[b]{2}{*}{ Semen $(\mathrm{ml})$} & \multirow{2}{*}{$\begin{array}{c}\text { Number of } \\
\text { ova transferred }\end{array}$} & \multirow{2}{*}{$\begin{array}{c}\text { Number of } \\
\text { shelled eggs laid }\end{array}$} & \multirow{2}{*}{$\begin{array}{l}\text { Percentage of } \\
\text { fertile eggs }\end{array}$} & \multicolumn{3}{|c|}{ Viability of embryos } & \multirow{2}{*}{$\begin{array}{c}\text { Number of } \\
\text { chicks hatched day } 21-22\end{array}$} \\
\hline & & & & day $1-4$ & day $5-9$ & day $10-19$ & \\
\hline 0.01 & 16 & 11 & $55(6 / 11)$ & 3 & 2 & I & 0 \\
\hline 0.05 & 27 & 22 & $55(12 / 22)$ & 2 & 2 & 2 & 6 \\
\hline 0.10 & 33 & 20 & $65(13 / 20)$ & 3 & 9 & 1 & 0 \\
\hline Control $^{b}$ & 10 & 10 & $100(10 / 10)$ & 1 & 0 & 0 & 9 \\
\hline Total & 86 & 63 & $65(41 / 63)$ & 9 & 13 & 4 & 15 \\
\hline
\end{tabular}

${ }^{a}$ Figures in parentheses indicate the number of fertilized eggs per shelled eggs laid.

${ }^{b}$ Oviductal ova ovulated following artificial insemination of hens were transferred to recipient hens and eggs laid were incubated. 
retrograde expulsion into the abdominal cavity. Although a fertility rate of $55-65 \%$ was obtained by IVF, only six of a total of 31 fertile eggs were hatched, because of losses during embryogenesis, particularly during the first 10 days of incubation. As eggs laid by hens in the control group had a $90 \%$ hatchability, such losses following IVF might have been due to excessive polyspermy, or to fertilization by damaged spermatozoa (Van Krey et al., 1966; Lorenz and Ogasawara, 1968) or to microbial contamination (Tanaka and Koga, 1971), as the so-called 'sperm selection mechanism' (Lorenz and Ogasawara, 1968) is absent in the IVF system. In addition, longer manipulation in vitro compared with controls, such as semen application and washing of the ovum, might have affected the viability of embryos. Moreover, the results indicate that the relative volume of semen to number of spermatozoa has an important influence on the hatchability of in vitro fertilized eggs, as only in the group in which $0.05 \mathrm{ml}$ of a 1:200 diluted semen was applied were live hatchlings obtained.

Howarth (1971) and Fujihara et al. (1973) showed that fowl spermatozoa do not require a period of capacitation within the reproductive tract of the hen. They cultured ova for $12-24 \mathrm{~h}$ after in vitro application of semen and examined the blastodisc of the ovum by histology. Our data support their observations and provide conclusive evidence that capacitation in the reproductive tract is not an essential feature of fertilization in fowl.

In a preliminary study, we attempted to incorporate MiwZ of linearized form into embryos of one-cell stage which were recovered from the anterior magnum, and transferred to recipient hens. Twenty shelled eggs were obtained of which three hatched and three embryos died during incubation. One embryo expressed MiwZ, but the hatchlings did not.

The authors are grateful to Professor T. Sasazuki, Faculty of Medicine, Kyushu University, for preparation of MiwZ.

\section{References}

Bogdonoff PD Jr and Shaffner CS (1954) The effect of $\mathrm{pH}$ on in vitro survival, metabolic activity, and fertilizing capacity of chicken semen Poultry Science $33665-669$

Freeman BM and Messer LI (1985) Genetic manipulation of the domestic fowl - a review World's Poultry Science Journal 41 124-132

Fujihara N, Tanaka K and Nishiyama J (1973) In vitro fertilization of fowl ova Japanese Journal of Zootechnical Science 44 564-568

Hamburger V and Hamilton L (1951) A series of normal stages in the development of the chick embryo joumal of Morphology 88 49-67

Howarth B Jr (1971) An examination for sperm capacitation in the fowl Biology of Reproduction 3 338-341

Howarth B Jr and Palmer MB (1972) An examination of the need for sperm capacitation in the turkey, Meleagris gallopavo Journal of Reproduction and Fertility 28 443-445

Lorenz FW and Ogasawara FX (1968) Distribution of spermatozoa in the oviduct and fertility in domestic birds journal of Reproduction and Fertility 16 $445-455$

Naito M, Nirasawa K and Oishi T (1990) Development in culture of the chick embryo from fertilized ovum to hatching Journal of Experimental Biology 254 $322-326$

Naito M, Agata K, Otsuka K, Kino K, Ohta M, Hirose K, Perry MM and Eguchi G (1991) Embryonic expression of $\beta$-actin-lac $Z$ hybrid gene injected into the fertilized ovum of the domestic fow! International Journal of Developmental Biology 35 69-75

Perry MM (1988) A complete culture system for the chick embryo Nature 331 $70-72$

Rowlett K and Simkiss K (1987) Explanted embryo culture: in vitro and in vivo techniques for domestic fowl British Poultry Science 28 91-101

Tanaka K and Koga $O$ (1971) Studies on the maintenance of fertilizing spermatozoa in the hen's oviduct Japanese Journal of Zootechnical Science $\mathbf{4 2}$ 237-249

Van Krey HP, Ogasawara FX and Lorenz FW (1966) Distribution of spermatozoa in the oviduct and fertility in domestic birds Journal of Reproduction and Fertility 11 257-262

Wilcox FH and Shaffner CS (1958) The effect of different handling methods and added fructose on the fertilizing ability of chicken spermatozoa after storage Poultry Science 39 1353-1357 